\title{
How to reduce workload - augmented reality to ease the work of air traffic controllers
}

\author{
Thomas Hofmann ${ }^{\mathrm{a}}$, Christina König ${ }^{\mathrm{b},}$ Ralph Bruder $^{\mathrm{b}}$ and Jörg Bergner ${ }^{\mathrm{c}}$ \\ ${ }^{a}$ Industrial Design, University of Applied Sciences Osnabrück, Vitihof 15a, 49074 Osnabrück, Germany \\ ${ }^{b}$ Institute of Ergonomics, Darmstadt University of Technology, Petersenstr. 30, 64287 Darmstadt, Germany \\ ${ }^{c}$ Forschung \& Entwicklung, DFS Deutsche Flugsicherung GmbH, Am DFS-Campus 5,63225 Langen, Germany
}

\begin{abstract}
In the future the air traffic will rise - the workload of the controllers will do the same. In the BMWi research project, one of the tasks is, how to ensure safe air traffic, and a reasonable workload for the air traffic controllers. In this project it was the goal to find ways how to reduce the workload (and stress) for the controllers to allow safe air traffic, esp. at huge hubairports by implementing augmented reality visualization and interaction.
\end{abstract}

Keywords: air traffic control, augmented reality, visualisation of complex conditions, reduction of head down times

\section{Introduction}

In the BMWi research project (iPort) one of the tasks was, how to ensure safe air traffic, and a reasonable workload for the air traffic controllers.

In this project it was the goal to find ways how to reduce the workload (and stress) for the controllers to allow secure air traffic, esp. at so-called huge hubairports.

The main task in this subproject was not to implement the technical equipment into the tower simulator but to get acceptance of the controllers presenting and interacting with the hard- and software. To get a most accepted design the users (controllers) were implemented in the whole development process of the HMI [6].

To ensure a high usability for the future user, a user-centred design process accordant to ISO 9241210 was applied [7].

\section{Method}

To be able to develop an innovative and ergonomic workspace, a new testbed was integrated into one of the tower simulators (ToSim II) of the German Air Navigation Service Provider (DFS) in Langen.
While the tower simulators of DFS are generally used for training of air traffic controllers, this testbed was especially designed and built support future research activities.

The setup was modified and adjusted especially for this project, used to implement different hard-, and software layouts to define a possible setup for future tower interior and workspace for ATC.

During the three iteration phases nine different air traffic controllers worked in this experimental testbed.

\subsection{Simulation setup}

To get valuable results of this concept design, a most realistic test environment is an essential aspect [5].

Especially at the controllers' work environment, which is characterized by high impact of the user, combined with high level of sensitivity to disturbances and modifications, a high level of reality is an essential character. The test setup was built up of the workplace of the controllers, several assistance workplaces and simulation pilots to simulate the air traffic (separate room). The setup was designed and evaluated by the project group (ergonomic experts and ATC experts (analogue to recommendation ISO

\footnotetext{
* Corresponding author. E-mail:
} 
9241-210)). The layout was designed as illustrated in Fig. 1.

Figure1

Simulation environment (draft)

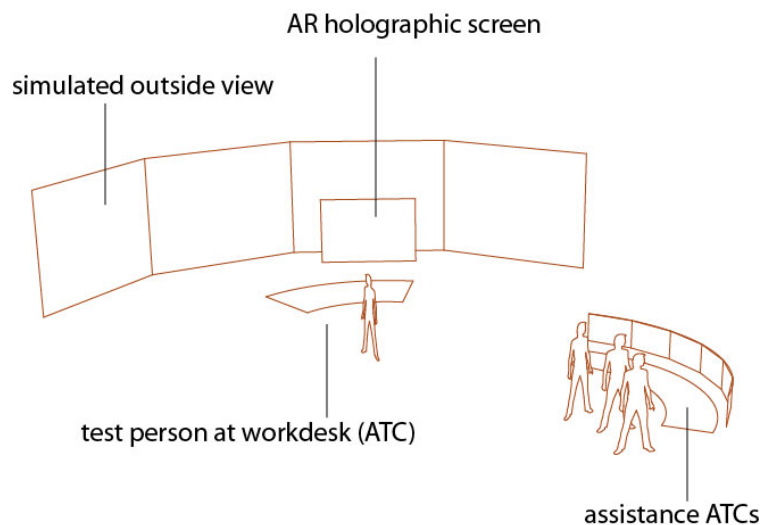

\section{Problem}

Air traffic controllers have to maintain situation awareness in a setting of rapidly changing information, retrieved from a wide array of information sources. They have to decide with conflicting goals and high responsibility under time constraints. This temporarily causes a tremendous cognitive workload

One of the most difficult and stressing situations for controllers is the coordination of information. On one hand (local area) the information delivered by the instruments at their work desk, the information received from other controllers in the room, the acoustic interaction with the pilots - on the other hand the information coming from outside (remote information) like: movement of airplanes, weather outside, light/darkness etc. [11] [10].

The controllers are confronted with a change of 'area of interest' up to 30 times per minute. Means: the controllers change their optical (and acoustical) focus every two seconds - including adaption of their eyes.

Because of the accommodation and focusing (motoric and mental workload), the primary concentration of the users drifts to basal interaction work [2].

Because of the continuous change of view and conditions of visualization, the concentration decreases fast.

The main focus of the research was how to optimize the information 'picking' in the future. The concept was to focus the interest of the controllers to the airfield and reduce the, head-down-times'. Each head-down / head-up movement cuts off the concentration to the primary interesting outside view, from where the controllers gets their primary control- and observation information [11].

\section{Concept}

The idea was to bring most of the primaryinformation, into the airfield'.

For this reason the idea to implement an augmented reality layer into the windows of the tower was born (head-up display).

The concept 'head-up display', used in military equipment, mobile devices or luxury cars is well known. But there are three significant differences to the concept described here:

- in most cases the display size used for this headup visualisation is very tiny, it uses only a very small screen or area of the field of view

- the user is positioned in a very fixed defined area

- most of the information are static and not aligned with 'real' information outside

In the present concept, the idea was:

- to use a large window screen of a future tower to present useful information to the controllers

- align the virtual information with the real outside information

- support the 'flexible working position' of the controllers

The reason for using the wide angle of view is based in the typical area the controllers are responsible for. They have to observe and control the complete length of a runway system (up to $3 \mathrm{~km}$ and more).

Because of the large amount of technical equipment the controllers move at their desk from left to right about 1-1.5 $\mathrm{m}$ - called 'flexible working position'.

For this reason the 'augmented reality' display (AR display) had to have a huge size.

\subsection{Test setup}

The main focus of this investigation was to get general information about the sense of implementing AR information for air traffic tower controllers.

For this reason, the setup had to be as comfortable as possible for the test person. The setup had to be 
implemented into the tower simulator additional to the regular setup - but not to disturb the user.

The projection plane for this AR information should be the tower window screen. The tower simulator does not have 'real' windows - because of this it was necessary to built up one that simulates windows.

To maximize the AR visualization quality a holographic equipped pane combined with a very bright full-HD video beamer was used to simulate a future window.

Figure 2

Simulation of tower window with holographic screen

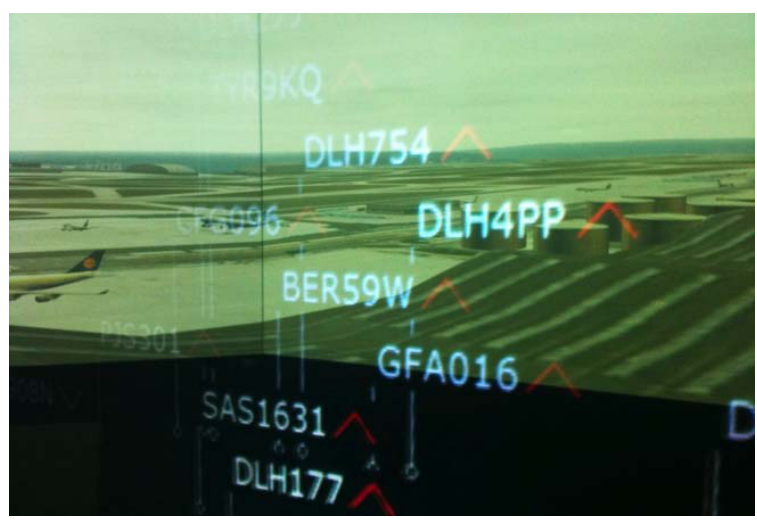

To provide the conjunction between virtual projection in the holographic screen and the 'real' (simulated) information outside - without influencing the workflow of ATC - a marker-less head tracker combined with interpreter software was used (Fig. 3).

Figure 3

Marker-less head tracker. Tracking works by using a webcam and tracking software

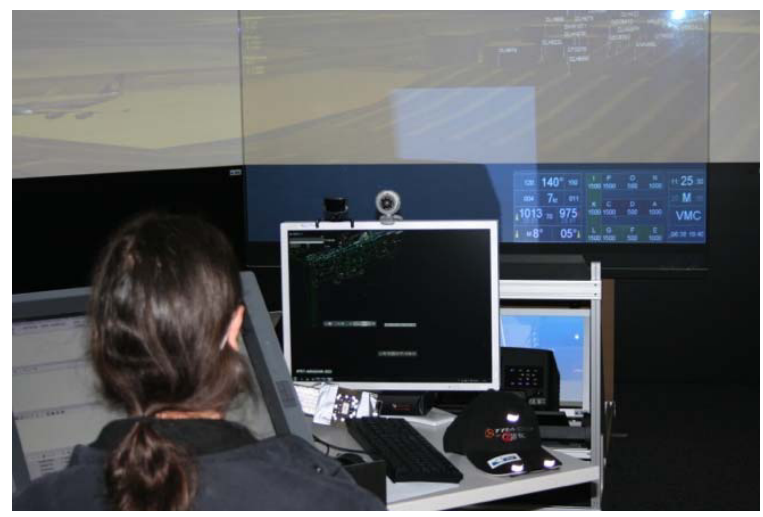

\section{Design process}

The implementation of $\mathrm{AR}$ information into a controller working position is a new research area.

The past investigations and design developments focused a very basic and fundamental ergonomic level.

There were some results in design for controller working position got in an earlier research project [4], but these designs were developed for pen interaction screens (WACOM). It was not possible to transfer the design to this project.

So it was necessary to adapt the design- and interaction to the new environment and interaction completely.

\subsection{First iteration}

An AR visualization varies from a traditional computer visualization in two fundamental characteristics:

- It is an additional information to the existing (on another physical layer)

- It is not possible to use black as colour

- The colour white reduces the transparency of the AR screen

These two characteristics influence the design development in different aspects:

- Because of the absence of black it is not possible to attenuate the background information as it is possible on typical computer monitors

- The range of possible colours is reduced to a very small range

- The more white is used, the less transparent the window will be

- As more information is displayed, the users get less information from outside

In the first step, visibility tests were made to define usable colours, text sizes, symbols (and details), line thickness etc. In Fig. 4 some of the tests patterns are shown.

Based on the test results (inquiries, reading tests, interviews), the first interface design were developed and tested (mock-up test without interaction). 
Figure $4(\mathrm{a}, \mathrm{b}, \mathrm{c})$

First test screens for AR visualization
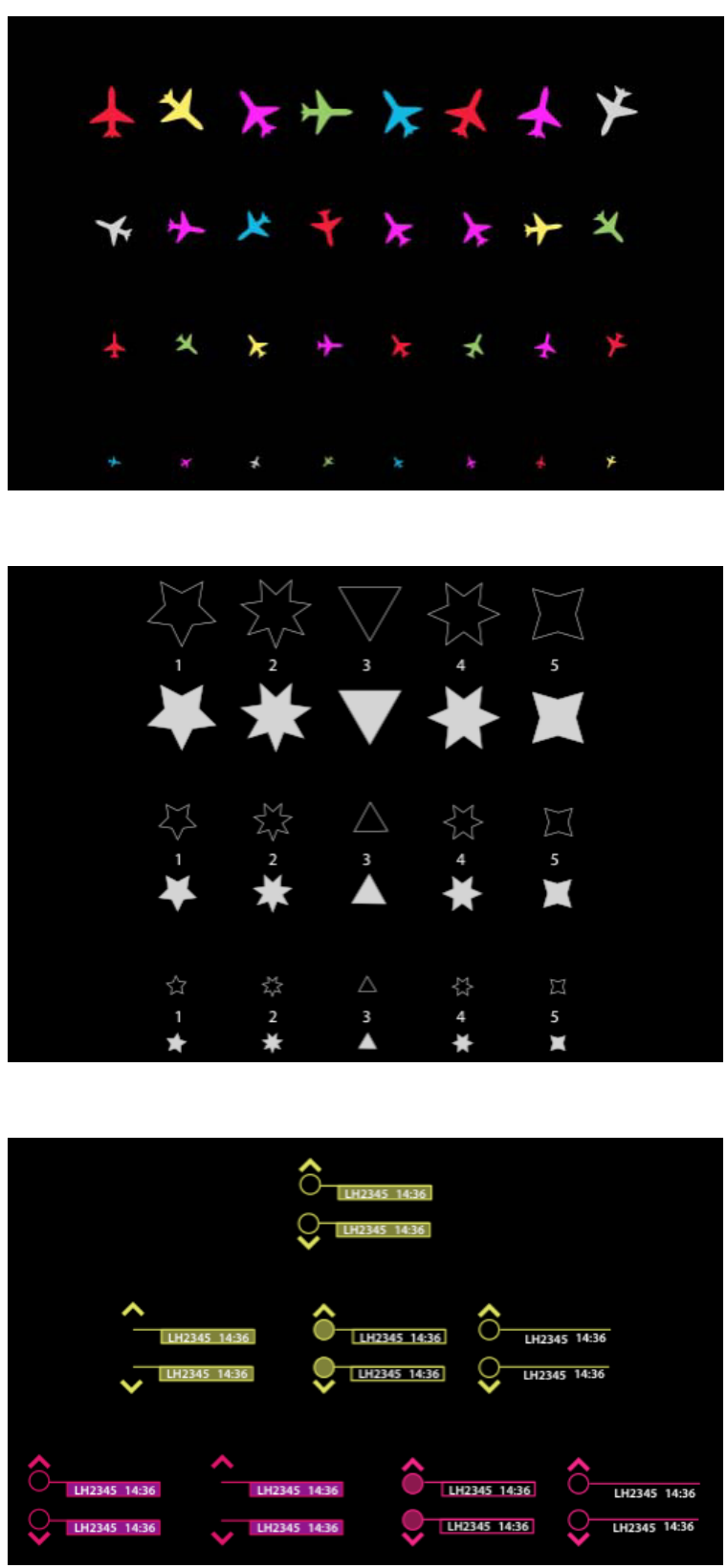

Results

The most interesting aspect was, the controllers accepted the idea to enrich the real information outside with virtual information. They reflected the first design with own ideas and requirements for the information visualisation.

However, they also expressed critic aspects:

- The visualisation should be as less as possible

- The visualisation has to be transparent

- The size on the screen (window) should not be too small (difficulty to read or interpret)

- The use of primary colours is a 'must'

\subsection{Second iteration}

In the next step the AR visualisation was combined with interaction. The information not only appeared on the AR screen, it was aligned with the outside (real) information. The head tracker recorded the 3D movement of the users head and "attached" the object information to the real object:

A call-sign visualsed in the AR seemed to stick at a moving/flying airplane. Additional information (weather, wind, list of airplane movements in the future) were positioned statically in corner of the screen. The colours, thickness of lines, symbols etc. were modified. In Fig. 5 some of the results are illustrated.

\section{Results}

The results of this second iteration were:

- It was no problem to match the virtual and real information although the information appeared on different layers (AR projection $3 \mathrm{~m}$ distance to the user, real object up to $6 \mathrm{~m}$ distance)

- The use of colours can be reduced to 3-4, the preferred colour for text information is white

- The resolution of the video projector must be very high, so that a single pixel is not recognizable by the user.

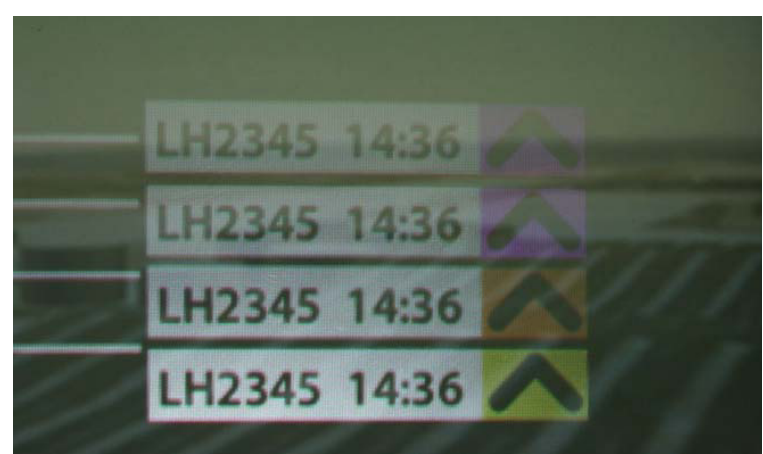



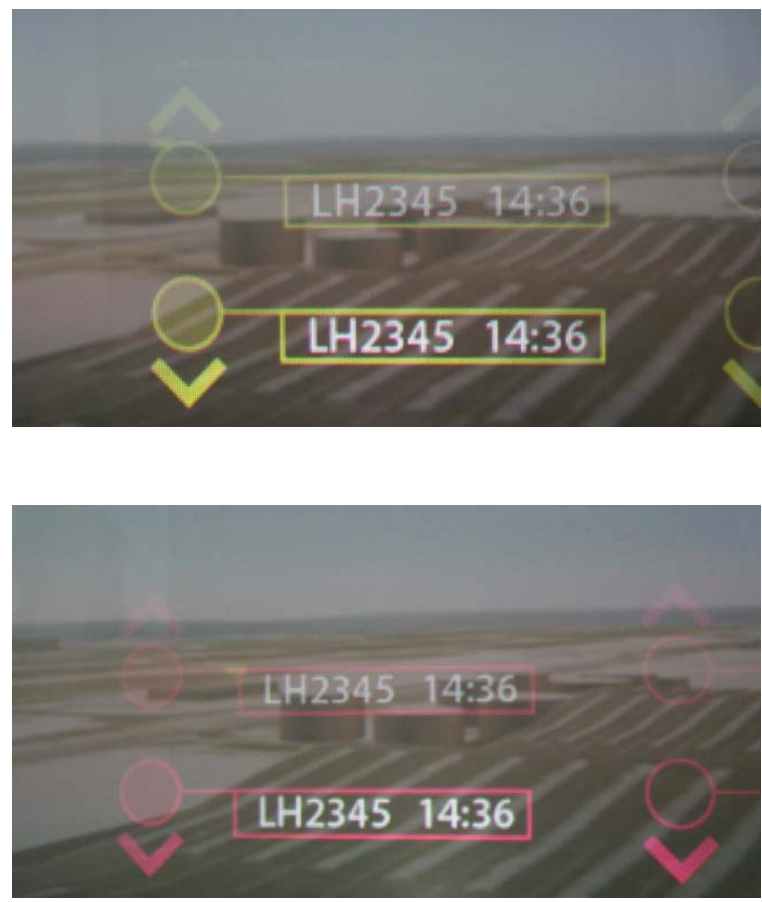

\subsection{Third iteration}

In the third simulation the modified design was tested in real simulation conditions, means the controllers had to work with the AR and real outside information and reduced information on their well known PC systems as well.

The results are as follows:

- The AR visualisation helped a lot, especially in the areas, were the controllers needs complex geographical based information (traffic jam at the start/end of the runway) and they typically have to switch between ground radar display and outside view

- The controllers appreciated the reduced head down times

\subsubsection{Results}

After three simulation runs, six different designconcepts, nine different users (air traffic controllers) and varying hardware setups the following results seem to be general characteristics:

- The information in an augmented reality layer should be less as possible

- The interface design must be as simple as possible and must not use any ,interpretable' graphic design
- An overlay on ,real' physical information outside is very difficult to read and confuses the controllers

- The massive use of colours in an AR-layer is not useful

- The combination of dynamic and static projection in the AR-layer generates some cognitive and visual problems

But in general: it seems to be very useful to implement AR-layer into the workplaces of the future, because the enrichment of information to the outside view enhances the usability and efficiency of the ATC work, esp. because of the less 'headdown-times'.

Figure 6

Test screens of the third iteration, AR visualization and outside view with interaction

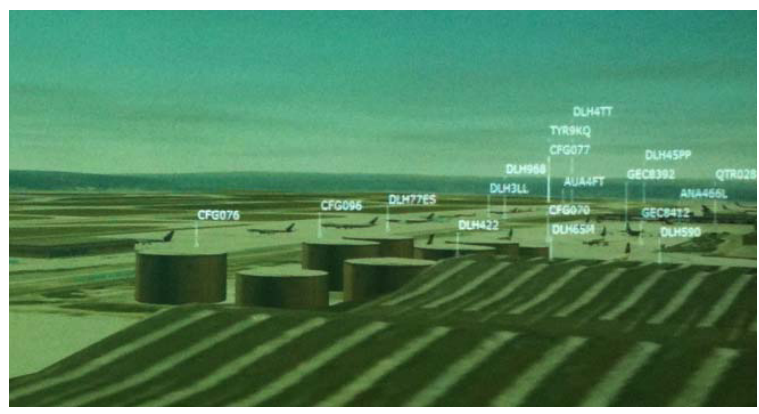

\section{Discussion}

In general it seems to be useful to implement ARlayer at a controller working position to reduce the workload. However, a simple transformation of "monitor-based" HMI design is not useful. It has to be adapted in a lot of characteristics. The development of AR HMI design needs a lot more research. It is much more connected to the work environment than conventional HMI - because in some aspects it is part of it.

Due to the special workspace of air traffic controllers (distances between interaction units and view to the airfield and -space) the content of augmented interfaces must be designed very carefully.

In the next steps the tests will be done under real conditions (in field tests). 


\section{Acknowledgements}

Thanks are due to our project team member Andreas Röbig (IAD) for setting up the AR hardware and to Daniel Strietholt for programming the AR environment an interaction procedures - without their knowledge this complex research were not be possible.

This work was in part funded by the German Federal Ministry of Economics and Technology (BMWi) within the forth national aerospace research program LuFo IV.

\section{References}

[1] Bergner, J., König, C., Hofmann, T., \& Ebert, H. (2009). An Integrated Arrival and Departure Display for the Tower Controller. Proceedings of 9th AIAA Aviation Technology, Integration, and Operations Conference, Hilton Head, SC, USA.

[2] Goldstein, E. B., \& Irtel, H. (2008). Wahrnehmungspsychologie : der Grundkurs (Bd. 7). Berlin $\{[$ u.a.]: Spektrum Akad. Verl.

[3] Hall, R. R. (2001). Prototyping for usability of new technology. International Journal of Human-Computer Studies, 55(4), 485-501.
[4] Hofmann, T., Bergner, J., König, C., Collaborating design massive cross-linked development, 1st. ErgoDesignForum, Lyon 2009

[5] ISO 9241-210 (2008): Ergonomics of human-system interaction - Part 210: Human-centred design process for interactive systems. Geneva: ISO.

[6] Jackson, T. F. (1980). System User Acceptance Thru System User Participation. Proceedings of the Annual Symposium on Computer Application in Medical Care, 3, 1715-1721

[7] König, C., Hofmann' T., Bruder' (2011), Application of usercentred design process according DIN EN ISO 9241-210 in air traffic control, Proceedings of IEA 2012, Recife, Brasil

[8] König, C., Hofmann, T., Bergner, J., Bruder, R., Inkrementelle nutzergerechte Etablierung eines Towerlotsen-HMI. Mensch \& Computer: 9. Fachübergreifende Konferen für interaktive und kooperative Medien. Grenzenlos frei?, 06. - 09. September 2009 in Berlin, Tagungsband. S. $63-72$

[9] König, C., Hofmann, T., Röbig, A., Bergner, J., (2010) Fluglotsen-Arbeitsplätze der Zukunft, In: Neue Arbeits- und Lebenswelten gestalten, 56. Frühjahrskongress der GfA, 24. - 26. März 2010 in Darmstadt, Tagungsband. Dortmund: GfA-Press

[10]Pinska, E., \& Bourgois, M. (2006). EUROCONTROL - Warsaw Tower Observations. EEC Technical/Scientific Report No. 2006-002. Brüssel: Eurocontrol

[11] Tavanti, M. (2006). Control Tower Operations: Roles Description. EEC Technical/Scientific Report No. 2006-012. Brüssel: Eurocontrol 